\title{
Decreased Colony-Forming Ability of Subacromial Bursa-Derived Cells During Revision Arthroscopic Rotator Cuff Repair
}

\author{
Daichi Morikawa, M.D., Ph.D., Matthew R. LeVasseur, M.D., S. Brandon Luczak, M.D., \\ Michael R. Mancini, B.S., Nicholas Bellas, M.D., Mary Beth R. McCarthy, B.S., \\ Mark P. Cote, D.P.T., M.S.C.T.R., Daniel P. Berthold, M.D., Lukas N. Muench, M.D., and \\ Augustus D. Mazzocca, M.S., M.D.
}

\begin{abstract}
Purpose: To compare the cellular viability and differentiation potential of subacromial bursa-derived cells (SBDCs) located over the rotator cuff muscle and tendon of patients undergoing primary versus revision arthroscopic rotator cuff repair (ARCR). Methods: Subacromial bursa was harvested from 18 primary (57.1 \pm 4.6 years) and 12 revision ARCRs (57.3 \pm 6.7 years). Bursa was collected from 2 sites (over rotator cuff tendon and muscle), digested with collagenase, and grown in culture. The number of nucleated cells, colony-forming units (CFUs), differentiation potential, and mesenchymal stem cell surface markers were compared in primary and revision cases. Results: There was no difference in the number of nucleated cells between primary and revision ARCR harvested from the subacromial bursa overlying the tendon (3019.3 \pm 1420.6 cells/mg and $3541.7 \pm 2244.2$ cells/mg, respectively; $P=.912)$ or muscle $(2753.5 \pm 1547.1$ cells/ $\mathrm{mg}$ and $2989.0 \pm 2231.4$ cells/mg, respectively; $P=.777)$. There was no difference in the number of CFUs between primary and revision ARCR over the rotator cuff tendon (81.5 \pm 49.5 CFUs and $53.0 \pm 36.9$ CFUs, respectively; $P=.138)$, but there were significantly fewer CFUs over the muscle in revision cases $(28.1 \pm 22.7$ CFUs) compared with primary cases (55.7 \pm 34.5 CFUs $)(P=.031)$. SBDCs from revision ARCR expressed characteristic mesenchymal stem cell surface epitopes and had multidifferentiation potentials for chondrogenesis, osteogenesis, and adipogenesis. Conclusions: SBDCs harvested over the rotator cuff muscle demonstrated significantly decreased colony-forming abilities in revision arthroscopic rotator cuff repairs compared with primary repairs. However, the subacromial bursa retains its pluripotent differentiation potential for chondrogenic, osteogenic, and adipogenic lineages in the revision setting. Clinical Relevance: The subacromial bursa may play a role in the healing response of the repaired rotator cuff. This capacity is not necessarily diminished in the revision setting and may be harnessed as an orthobiologic.
\end{abstract}

$\mathbf{R}$ etears of the rotator cuff remain a problem in shoulder surgery, with rates ranging from $13 \%$ to $96 \% .^{1-4}$ As such, these recurrent and oftentimes chronic tears burden the patient with pain and disability as well as yield a significant health care cost. Despite

From the Department of Orthopaedic Surgery, University of Connecticut, Farmington, Connecticut, U.S.A. (D.M., M.R.L., B.L., M.R.M., N.B., M.B.R.M, M.P.C., D.P.B., L.N.M., A.D.M.); Department of Orthopaedic Surgery, Juntendo University, Tokyo, Japan (D.M.); and Department of Orthopaedic Sports Medicine, Technical University of Munich, Munich, Germany (D.P.B., L.N.M.).

The authors report the following potential conflicts of interest or sources of funding: M.P.C. receives personal fees from Arthroscopy Association of North America (AANA), outside of the submitted work. A.D.M. reports research grants from Arthrex and is a consultant for Arthrex. The University of Connecticut Health Center/UConn Musculoskeletal Institute has received direct funding and material support from Arthrex. The company had no influence on study design, data collection, or interpretation of the results or the final advances in technique and biomechanical constructs for rotator cuff repair, many recent investigations suggest the limited healing potential is a biologic problem. ${ }^{5,6}$ Consequently, various biologic augmentations have been explored, including scaffolds, concentrated bone

manuscript. Full ICMJE author disclosure forms are available for this article online, as supplementary material.

This investigation was performed at the Department of Orthopaedic Surgery, University of Connecticut, Farmington, Connecticut, U.S.A.

Received December 6, 2020; accepted March 14, 2021.

Address correspondence to Matthew R. LeVasseur, M.D., 263 Farmington

Ave.,Farmington, CT 06030.E-mail:mlevasseur@uchc.edu

(C) 2021 THE AUTHORS. Published by Elsevier Inc. on behalf of the Arthroscopy Association of North America. This is an open access article under the CC BY-NC-ND license (http://creativecommons.org/licenses/by-nc-nd/4.0/). 2666-061X/201919

https://doi.org/10.1016/j.asmr.2021.03.010 
marrow aspirate, platelet-rich plasma, and subacromial bursa-derived cells (SBDCs) as a source of mesenchymal stem cells (MSCs). ${ }^{7-9}$ Recent literature has identified MSCs, also known as connective tissue progenitor cells (CTPs), in the subacromial bursa, fulfilling the criteria by the International Society for Cellular Therapy for similar cell surface markers and the potential for adipogenic, osteogenic, and chondrogenic differentiation. ${ }^{10,11}$ The therapeutic role of MSCs derived from the subacromial bursa is the subject of many recent investigations, favoring its easy accessibility and inexpensiveness during arthroscopic rotator cuff repair (ARCR). ${ }^{12-16}$

Although the precise role of the subacromial bursa remains to be fully understood, it is believed to have a role in the healing response. ${ }^{10,12-14,17-19}$ Uhthoff and Sarkar ${ }^{10}$ suggest that the subacromial bursa reflects a reparative response rather than a consequence of degeneration. Namely, the subacromial bursa has been shown to manifest hyperplasia, neoangiogenesis, and hypertrophy, all suggestive of their potential role in the healing of rotator cuff tears. ${ }^{17,18}$ Failed rotator cuff repairs have shown evidence of hypovascularity; ergo, further removal of the subacromial bursa may hinder the native healing response. Moreover, complications and failure rates increase with the number of attempts at arthroscopic repair, most commonly secondary to poor tissue integrity. ${ }^{20}$ Utsunomiya et al. ${ }^{21}$ identified the cells from the subacromial bursa having superior proliferation potential and colony-forming capabilities compared with those from the synovium, tendon margin, and enthesis. Morikawa et al. ${ }^{12}$ identified superior differentiation and proliferation potentials of SBDCs compared with concentrated bone marrow aspirate from the proximal humerus. In a recent study by Muench et al. ${ }^{14}$ investigating the role of patient demographics and rotator cuff characteristics on cellular proliferation of SBDCs, these authors identified high proliferation potential irrespective of these factors, including primary and revision cases. However, this study did not investigate the colony forming or differentiation potentials of these cells.

Overall, there is limited information on the cellular viability and differentiation potential of SBDCs for bone, fat, and cartilage formation in the revision rotator cuff repair setting. This information will help determine appropriate options for biologic augmentation during revision repairs. The purpose of this study was to compare the cellular viability and differentiation potential of SBDCs located over the rotator cuff muscle and tendon of patients undergoing primary versus revision ARCR. The authors hypothesized that there would be no difference in the nucleated cell count, colony-forming ability, and differentiation potential of SBDCs between primary and revision cases from the bursa overlying the muscle belly and tendon.

\section{Methods}

Before the initiation of the study, institutional review board approval was obtained (University of Connecticut \#IE-07-224-2). Nonconsecutive patients were enrolled from a single surgeon's practice (A.D.M.) from November 2016 to May 2018. Included in the study were patients 18 years and older undergoing primary or revision ARCR for a full-thickness tear of at least 1 tendon. Patients were excluded if they were of a vulnerable patient population, including prisoners or pregnant women, as well as patients with systemic infectious diseases (e.g., hepatitis or human immunodeficiency virus) for laboratory safety. Subacromial bursa was harvested from 2 sites: over the rotator cuff tendon and over the rotator cuff muscle. ${ }^{12}$ Nucleated cell count, colony-forming units (CFUs), differentiation potential, and MSC surface markers from both types of bursa were compared between the primary and revision ARCR groups.

\section{Subacromial Bursa Collection and Isolation}

During arthroscopic evaluation using a lateral viewing portal, subacromial bursa was obtained using an arthroscopic grasper device passed through the posterior portal from 2 sites: over the rotator cuff tendon and over the muscle. ${ }^{13}$ Harvesting was completed once at least $0.2 \mathrm{~g}$ was obtained for each sample. The samples were then placed in separate sterile specimen cups filled with saline and transported immediately to the laboratory for processing in a laminar flow hood. Initial digestion was completed mechanically using scissors sterilized with 70\% ethanol for 60 seconds until the tissue was finely minced. Both specimens were then separately digested in $2 \mathrm{mg} / \mathrm{mL}$ Collagenase $\mathrm{P}$ (Sigma-Aldrich, St. Louis, MO) in Dulbecco's modified Eagle's medium (DMEM) (1×; Thermo Fisher Scientific, Waltham, MA) at $37^{\circ} \mathrm{C}$ for 2 hours. Following digestion, the cells were filtered through a $70-\mu \mathrm{m}$ cell strainer (Fisher Scientific, Pittsburgh, PA), the remnant was disposed of and the cells were centrifuged at $800 \mathrm{~g}$ for 5 minutes to obtain a cell pellet. ${ }^{11}$

\section{Nucleated Cell Count}

After digestion, the cellular concentrations (cells/ $\mathrm{mL}$ ) were counted using a Zl Coulter Particle Counter (Beckman Coulter Life Sciences, Indianapolis, IN), calibrated to detect particles $>8 \mu \mathrm{m}$, using a transparent cuvette containing $100 \mu \mathrm{L}$ of cellular solution and $9.9 \mathrm{~mL}$ of $0.9 \% \mathrm{NaCl}$ solution for a total volume of $10 \mathrm{~mL}$. From this cellular concentration, the number of nucleated cells could be calculated by multiplying by the volume of DMEM (10 mL). The cell mass density (cells/mg) could then be calculated by normalizing with respect to the total mass of the harvested tissue. 


\section{Colony-Forming Units}

After nucleated cell count, the cells were then plated in complete culture medium containing DMEM, 10\% fetal bovine serum (FBS) (Thermo Fisher Scientific), and $0.1 \%$ penicillin/streptomycin (Thermo Fisher Scientific). The cells were plated in Corning Primaria 100$\mathrm{mm}$ dishes (Thermo Fisher Scientific) at a density of $10^{3}$ and were grown at $37^{\circ} \mathrm{C}$ in a $5 \%$ humidified $\mathrm{CO}_{2}$ incubator. ${ }^{11,21}$ Complete DMEM medium was changed every 3 to 4 days. After 14 days in culture, 3 dishes of each density were stained with $0.5 \%$ crystal violet solution for 10 minutes. The cells were then washed twice with distilled water, and the number of colonies per dish was counted. Colonies measuring $<2 \mathrm{~mm}$ in diameter or faintly stained colonies were not included. ${ }^{13,21,22}$

\section{Flow Cytometry}

According to the International Society for Cellular Therapy, one criterion for cells to be considered MSCs is positive CD105, CD90, and CD73 surface markers and the absence of hematopoietic surface markers CD45 and CD $31 .{ }^{23}$ These epitopes were measured using fluorescence-activated cell sorting with a BD LSR II flow cytometer (BD Biosciences). First, the passage-3 cells were liberated from the culture dishes using sterile $0.5 \%$ trypsin/EDTA. The $\mathrm{Zl}$ Coulter Counter was used to determine cellular concentrations and one million passage- 3 cells were resuspended in $100 \mu \mathrm{L}$ of staining buffer $(1 \times$ phosphate-buffered saline with $1 \%$ FBS and $1 \%$ human serum) containing a fluorescein isothiocyanate or phycoerythrin antibody. All antibodies were obtained from BD Biosciences (San Diego, CA). Flow cytometry was completed on 4 patient samples from revision cases due to the expensive nature of this test. Data were analyzed using BD FACSDiva software (BD Biosciences).

\section{Chondrogenic Differentiation}

The methodology for chondrogenic differentiation was derived from a previous study. ${ }^{24}$ To start, 250,000 passage -3 cells from subacromial bursa were placed in a 15-mL polypropylene tube (Falcon; BD, Franklin Lakes, $\mathrm{NJ})$ and centrifuged at $450 \mathrm{~g}$ for 10 minutes to create cellular pellets. The pellets were cultured in $400 \mu \mathrm{L}$ of chondrogenic medium containing high-glucose DMEM, $10 \mathrm{ng} / \mathrm{mL}$ transforming growth factor- $\beta-1$ (R\&D Systems, Minneapolis, MN), $100 \mathrm{nM}$ dexamethasone (Sigma-Aldrich), $\quad 50 \mu \mathrm{g} / \mathrm{mL}$ ascorbate-2-phosphate (Sigma-Aldrich), $40 \mu \mathrm{g} / \mathrm{mL}$ proline (Sigma-Aldrich), $100 \mu \mathrm{g} / \mathrm{mL}$ pyruvate (Sigma-Aldrich), and $50 \mathrm{mg} / \mathrm{mL}$ liquid media supplement (ITS+1; Sigma-Aldrich; containing bovine insulin, human transferrin, sodium selenite, bovine serum albumin, and linoleic acid). The medium was replaced every 3 to 4 days for 3 weeks. At day 21 , the size and weight of the cellular pellets were measured and compared for each sample. For histologic examination, the pellets were stained with Toluidine blue, Alcian Blue, and type II collagen following alcohol dehydration, paraffin embedding, and sectioning (5$\mu \mathrm{m}){ }^{21,24,25}$

\section{Osteogenic Differentiation}

First, 100 passage-2 cells from both types of subacromial bursa were plated in 100-mm dishes and cultured for 14 days in complete DMEM. The cells were then fed an osteogenic differentiation medium containing DMEM, 10\% FBS, $1 \mathrm{nM}$ dexamethasone, 20 $\mathrm{mM} \beta$-glycerophosphate, and $50 \mu \mathrm{g} / \mathrm{mL}$ ascorbate-2 phosphate for an additional 21 days. $^{22}$ Following $100 \%$ methanol fixation, mineralized bone nodule formation from each sample was assessed by Alizarin Red staining.

\section{Adipogenic Differentiation}

First, 100 passage- 2 cells from both of the subacromial bursa types were plated in 100-mm dishes and cultured in complete DMEM for 14 days. ${ }^{25}$ The cells were then treated with adipogenic medium for 21 days containing DMEM, 10\% FBS, $100 \mathrm{nM}$ dexamethasone, $0.5 \mathrm{mM}$ isobutyl-1-methylxanthine (Sigma-Aldrich), and 50 $\mu \mathrm{M}$ indomethacin (Sigma-Aldrich). The cells were stained with fresh Oil Red-O (Sigma-Aldrich) solution following fixation in $70 \%$ ethanol. ${ }^{21,22,25}$

\section{Statistical Analysis}

For statistical analysis, continuous variables were presented as means and standard deviations and categorical variables were summarized using frequencies and proportions. Differences in cell density (cells/mg) and CFUs over the muscle and tendon were evaluated using the Mann-Whitney $U$ test. A $P$ value of $<.05$ was considered statistically significant. All statistical analyses were performed with EZR (Saitama Medical Center, Jichi Medical University, Saitama, Japan), which is a graphical user interface for $\mathrm{R}$ (The R Foundation for Statistical Computing, Vienna, Austria). More precisely, it is a modified version of $\mathrm{R}$ commander designed to add statistical functions frequently used in biostatistics. ${ }^{26}$

\section{Results}

Eighteen patients who underwent primary ARCR and 12 patients who underwent revision ARCR were included in the study. The patient age was $57.1 \pm 4.6$ years and $57.3 \pm 6.7$ years for primary and revision cases, respectively. There were equal male $(n=9)$ and female $(\mathrm{n}=9)$ patients in the primary group. There were 8 male and 4 female patients in the revision group. The rotator cuff tear size based on preoperative magnetic resonance imaging was $17.9 \pm 9.1 \mathrm{~mm}$ and $32.0 \pm 13.9 \mathrm{~mm}$ for primary and revision cases, 
Table 1. Patient Demographics and Preoperative Tear Characteristics

\begin{tabular}{|c|c|c|c|c|}
\hline \multirow[b]{2}{*}{ Characteristic } & \multicolumn{2}{|c|}{ Primary } & \multicolumn{2}{|c|}{ Revision } \\
\hline & Mean \pm SD & Range & Mean \pm SD & Range \\
\hline$\overline{\text { Age, } y}$ & $57.1 \pm 4.6$ & $50-67$ & $57.3 \pm 6.7$ & $46-67$ \\
\hline Tear size, mm & $17.9 \pm 9.1$ & $8.8-37.5$ & $32.0 \pm 13.9$ & $8.4-50.0$ \\
\hline Symptom duration, mo & $8 \pm 9$ & $1-9$ & $8 \pm 6$ & $1-21$ \\
\hline \multirow[t]{2}{*}{ Time since primary, mo } & & & $83 \pm 77$ & $5-227$ \\
\hline & $\mathrm{N}$ & $\%$ & $\mathrm{~N}$ & $\%$ \\
\hline \multicolumn{5}{|l|}{ Sex } \\
\hline Female & 10 & $56 \%$ & 4 & $33 \%$ \\
\hline Male & 8 & $44 \%$ & 8 & $67 \%$ \\
\hline \multicolumn{5}{|l|}{ Dominant arm } \\
\hline Yes & 8 & $44 \%$ & 6 & $50 \%$ \\
\hline No & 10 & $56 \%$ & 6 & $50 \%$ \\
\hline \multicolumn{5}{|l|}{ Diabetes } \\
\hline Yes & 5 & $28 \%$ & 3 & $25 \%$ \\
\hline No & 13 & $72 \%$ & 9 & $75 \%$ \\
\hline \multicolumn{5}{|l|}{$\begin{array}{l}\text { Inflammatory } \\
\text { arthropathy }\end{array}$} \\
\hline Yes & 0 & $0 \%$ & 1 & $8 \%$ \\
\hline No & 18 & $100 \%$ & 11 & $92 \%$ \\
\hline \multicolumn{5}{|l|}{ Smoker } \\
\hline Current & 3 & $17 \%$ & 5 & $42 \%$ \\
\hline Former & 7 & $39 \%$ & 2 & $17 \%$ \\
\hline Never & 8 & $44 \%$ & 5 & $42 \%$ \\
\hline \multicolumn{5}{|l|}{ Previous treatments } \\
\hline PT & 12 & $67 \%$ & 8 & $67 \%$ \\
\hline NSAIDs & 14 & $78 \%$ & 8 & $67 \%$ \\
\hline $\begin{array}{l}\text { Corticosteroid } \\
\text { injection }\end{array}$ & 6 & $33 \%$ & 3 & $25 \%$ \\
\hline PRP & 0 & $0 \%$ & 1 & $8 \%$ \\
\hline BMAC & 0 & $0 \%$ & 1 & $8 \%$ \\
\hline \multicolumn{5}{|l|}{ Muscle atrophy* } \\
\hline None & 9 & $50 \%$ & 2 & $17 \%$ \\
\hline Mild & 3 & $17 \%$ & 2 & $17 \%$ \\
\hline Moderate & 4 & $22 \%$ & 3 & $25 \%$ \\
\hline Severe & 2 & $11 \%$ & 5 & $42 \%$ \\
\hline \multicolumn{5}{|l|}{ Fatty infiltration } \\
\hline Goutallier 0 & 8 & $44 \%$ & 2 & $17 \%$ \\
\hline Goutallier 1 & 1 & $6 \%$ & 1 & $8 \%$ \\
\hline Goutallier 2 & 4 & $22 \%$ & 2 & $17 \%$ \\
\hline Goutallier 3 & 3 & $17 \%$ & 3 & $25 \%$ \\
\hline Goutallier 4 & 2 & $11 \%$ & 4 & $33 \%$ \\
\hline
\end{tabular}

BMAC, bone marrow aspirate stem cell concentrate; NSAIDs, nonsteroidal anti-inflammatory drugs; PRP, platelet-rich plasma; PT, physical therapy; SD, standard deviation.

* Muscle atrophy graded according to Warner et al. ${ }^{27}$

respectively. Patient demographics and preoperative tear characteristics are shown in Table $1 .{ }^{27}$

\section{Nucleated Cell Count}

Subacromial bursa cells from primary and revision ARCR showed no difference in nucleated cell number per milligram (Fig 1). Subacromial bursa cells over the rotator cuff tendon revealed $3019.3 \pm 1420.6$ cells $/ \mathrm{mg}$ (range, 748.3 to 5695.9 cells/mg) for primary ARCR and $3541.7 \pm 2244.2$ cells/mg (range, 1166.7 to 8331.1 cells $/ \mathrm{mg})$ for revision ARCR $(P=.912)$. Subacromial bursa cells over the rotator cuff muscle revealed 2753.5 \pm 1547.1 cells $/ \mathrm{mg}$ (range, 338.1 to 5704.7 cells $/ \mathrm{mg}$ ) for primary ARCR and $2989.0 \pm 2231.4$ cells/mg (range, 1121.0 to 7705.4 cells $/ \mathrm{mg}$ ) for revision ARCR $(P=.777)$.

\section{Colony-Forming Units}

Subacromial bursa cells from primary and revision ARCR showed no difference in CFUs for bursa over the rotator cuff tendon but showed a significant difference for bursa over the rotator cuff muscle (Fig 2). Subacromial bursa cells over the tendon revealed $81.5 \pm$ 49.5 CFUs per $10^{3}$ plated cells (range, 10.0-197.7 CFUs) for primary ARCR and 53.0 \pm 36.9 CFUs (range, 16.7141.3 CFUs) for revision ARCR $(P=.138)$. Subacromial bursa cells over the rotator cuff muscle revealed significantly more CFUs for primary ARCR ( $55.7 \pm 34.5$ CFUs; range, 4.7-135.0 CFUs) compared with 28.1 \pm 22.7 CFUs (range, 7.0-89.0 CFUs) for revision ARCR $(P=.031)$.

\section{Cell Cytometry}

Subacromial bursa cells derived from patients undergoing revision ARCR expressed characteristic MSC markers defined by the International Society for Cellular Therapy. ${ }^{23}$ All patient samples expressed CD105, CD90, and CD73 and lacked expression of hematopoietic surface markers CD45 and CD31 (Fig 3). The positivity rate for CD105 was $98.3 \pm 0.6 \%$, CD90 was $99.6 \pm 0.2 \%$, and CD73 was $94.7 \pm 1.1 \%$. The positivity rate for $\mathrm{CD} 45$ was $0.0 \pm 0.0 \%$ and CD3l was $0.0 \pm 0.1 \%$.

\section{Cellular Differentiation}

Chrondrogenesis was evaluated using a pellet culture system. ${ }^{21,24}$ The pellets over the rotator cuff tendon and muscle exhibited strong staining of cartilage extracellular matrix for both primary and revision ARCR. Cartilage extracellular matrix staining was assessed by Toluidine blue, Alcian Blue, and type II collagen (Fig 4A).

Osteogenesis was evaluated using a colony-forming assay with Alizarin Red to determine calcification. Subacromial bursa over the rotator cuff tendon and muscle demonstrated a large quantity of Alizarinpositive staining colonies in both primary and revision cases (Fig 4B).

Adipogenesis was evaluated using a colony-forming assay with Oil Red-O. Subacromial bursa over the rotator cuff tendon and muscle demonstrated a large quantity of Oil Red-O-positive staining colonies in both primary and revision cases (Fig 4C).

\section{Discussion}

The most important finding of this study is that there were significantly fewer CFUs of CTPs derived from the subacromial bursa over the rotator cuff muscle in patients undergoing revision ARCRs compared with 


\section{Nucleated cell number per milligram}
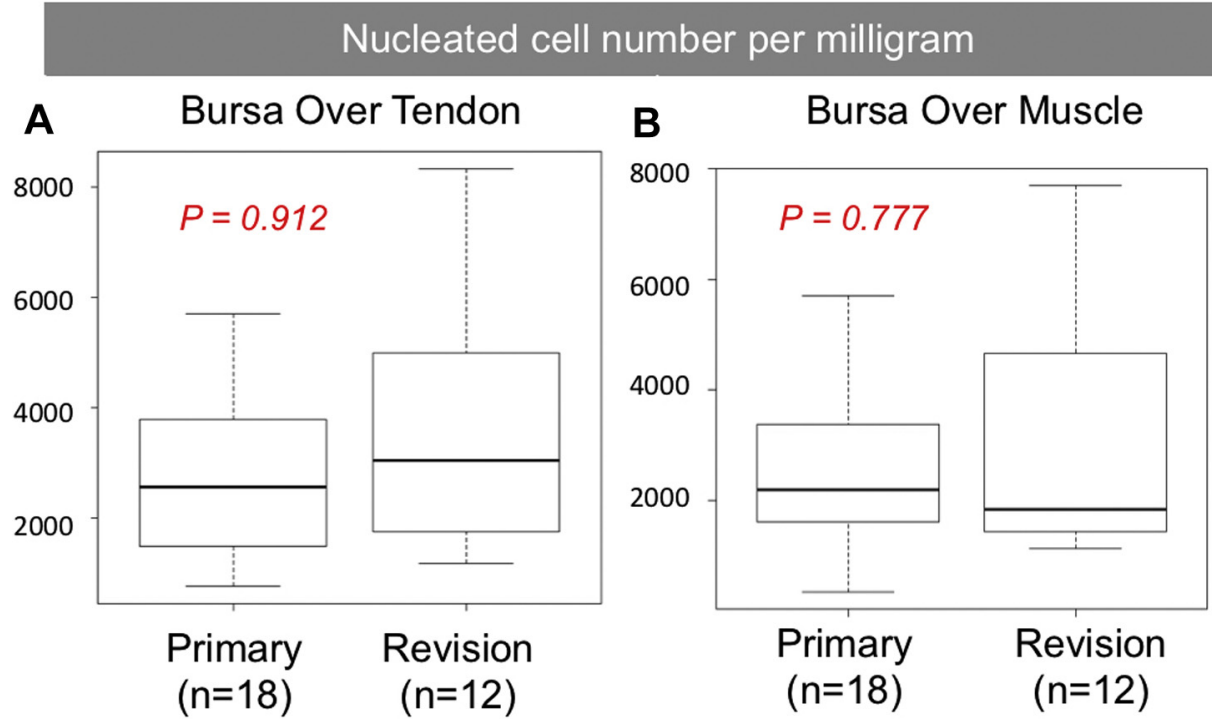

Fig 1. Nucleated cell count per milligram for primary and revision ARCR from the subacromial bursa overlying the rotator cuff (A) tendon and (B) muscle belly. No significant differences were identified. (ARCR, arthroscopic rotator cuff repairs.)

primary repairs. On the contrary, the number of CFUs from bursa samples harvested from over the rotator cuff tendon was not significantly different between primary and revision cases. There were similar numbers of nucleated cells per milligram in the subacromial bursa between primary and revision ARCR, both overlying the rotator cuff tendon and muscle. Importantly, CTPs harvested during revision ARCR were able to maintain their differentiation potential for cartilage, bone, and adipose formation. These findings demonstrate that SBDCs maintain their cellular viability and differentiation potential in a revision ARCR setting and may be used for augmentation in the challenging treatment of recurrent rotator cuff tears.
Despite advances in surgical technique and biomechanical stability of primary rotator cuff tendon repair, the failure rate remains significant. Recurrent tears after primary ARCR range between $20 \%$ and $40 \%$ for small to medium tears and as high as $94 \%$ for large or chronic tears. ${ }^{2,28-31}$ Revision rotator cuff repair is an even more challenging problem with significantly greater risk of failure and worse patient outcomes. ${ }^{32}$ The main mode of failure of ARCR is a lack of regeneration of the bone-tendon enthesis, often healing with a weaker fibrovascular, disorganized scar. ${ }^{33}$ This has led to investigation into ways to augment the biological milieu surrounding the rotator cuff repair in an attempt to improve healing rates. ${ }^{34,35}$

\section{Number of colony forming units}

\section{A Bursa Over Tendon}

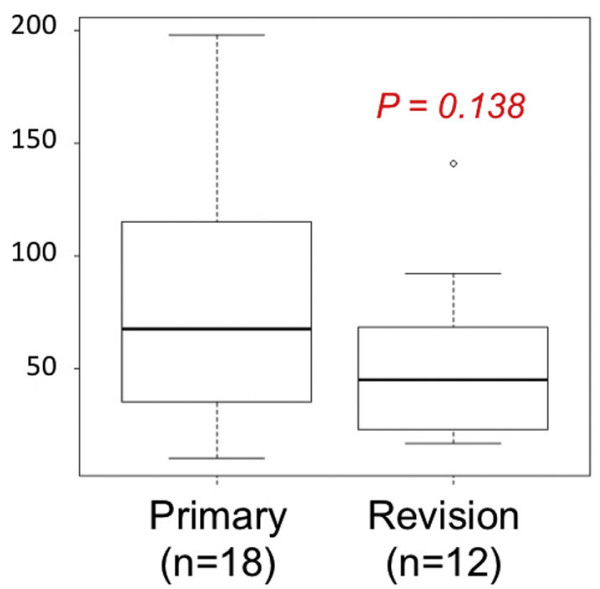

\section{B Bursa Over Muscle}

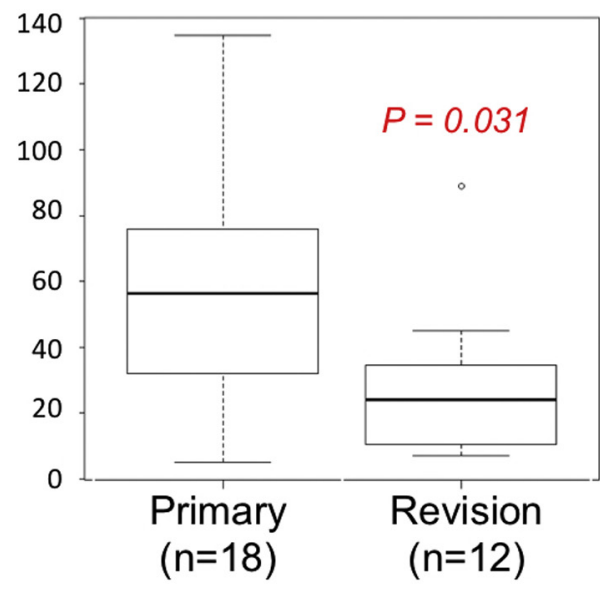

Fig 2. CFUs per $10^{3}$ cells in primary and revision ARCR from the subacromial bursa overlying the rotator cuff (A) tendon and (B) muscle belly. There was no difference in the number of CFUs overlying the tendon; however, there was a statistically significant decrease in the number of CFUs in the subacromial bursa overlying the muscle belly in revision cases. (ARCR, arthroscopic rotator cuff repairs; CFU, colony-forming unit.) 


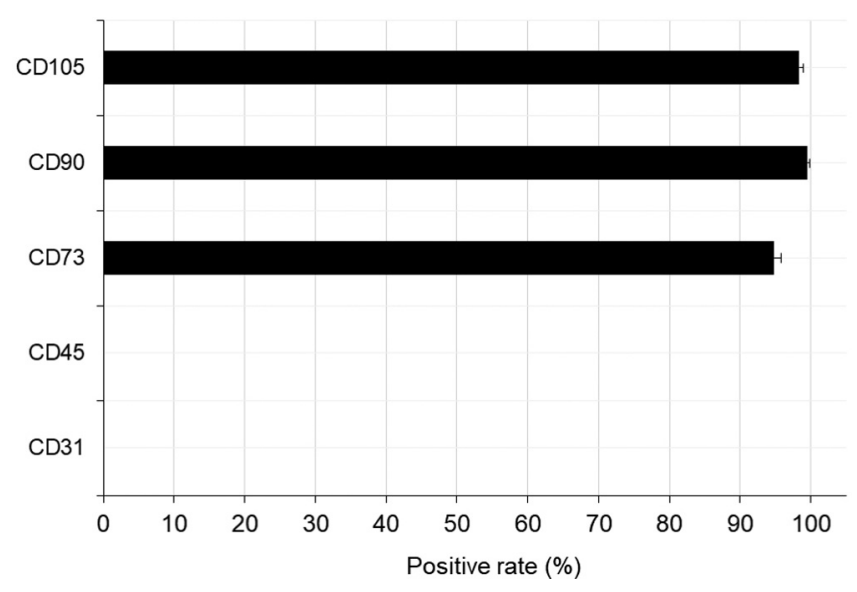

Fig 3. Surface epitopes of subacromial bursa-derived cells from revision ARCR. These cells expressed high positivity for CD105, CD90, and CD73 and lacked expression of the hematopoietic surface markers CD45 and CD31, supporting the criteria for MSCs by the International Society for Cellular Therapy. $^{23}$ (ARCR, arthroscopic rotator cuff repairs; MSC, mesenchymal stem cell.)

One such augment has been the incorporation of MSCs, also known as CTPs. ${ }^{36-38}$ These cells have been identified in the subacromial bursa in large quantities. Song et al. ${ }^{39}$ demonstrated that the bursa tissue contained cells that exhibited high proliferative capacity and differentiated toward cells of mesenchymal lineages with high efficiency. They also were able to demonstrate in vivo that these cells could form tendonlike and fibrocartilaginous tissue in ceramic scaffolds. Similarly, Utsunomiya et al. ${ }^{21}$ studied the potency of MSCs between cells derived from various tissues within the same shoulder and found that subacromial bursa tissue had the greatest potency of MSCs. Morikawa et al. ${ }^{12}$ further delineated the potency of SBDCs by comparing them with concentrated bone marrow aspirate from the proximal humerus at time of rotator cuff repair. They demonstrated that bursal cells had significantly increased differentiation ability and gene expression over time compared with concentrated bone marrow aspirate from the proximal humerus.

Interestingly, Muench et al. ${ }^{14}$ investigated the role of patient demographics and rotator cuff characteristics on cellular proliferation of SBDCs, defined as the number of nucleated cells per mass of plated tissue following 3 weeks in culture. These authors identified high proliferation potentials irrespective of these factors, including primary and revision cases. However, nucleated cell count is a nonspecific measure of SBDC activity and does not confirm nor refute the presence of CTPs. Nucleated cell count also is unable to differentiate between live or dead cells and cannot distinguish CTPs from other mononuclear cells, including those of hematologic origin. Moreover, similar to the current study, reported nucleated cell counts are highly variable between patients, which may limit their clinical utility. ${ }^{12,14}$ CFUs may be more clinically relevant, as the characteristic microscopic appearance of MSCs is appreciated and the formed colonies represent collections of viable cells. Moreover, differentiation into cartilage, bone, and adipose further supports the harvesting of CTPs.

Morikawa et al. ${ }^{12}$ further characterized the difference in SBDCs between the bursa over the rotator cuff tendon and the muscle belly in primary cases. In that

\section{A}

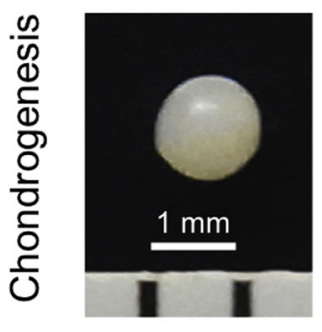

B

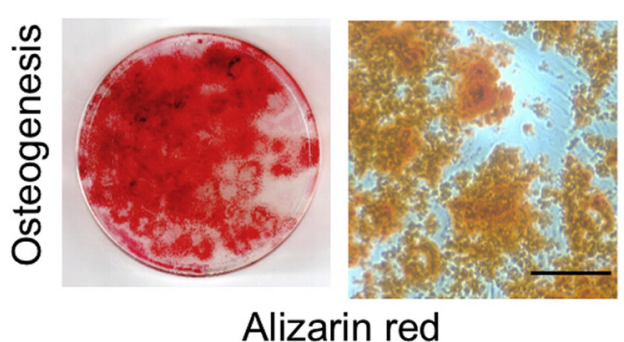

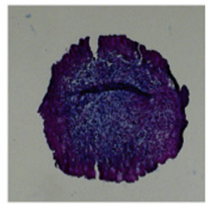

Alcian blue

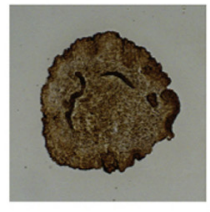

Toluidine blue

C

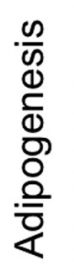

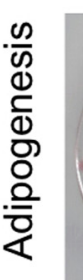

$0.5 \mathrm{~mm}$

Fig 4. Differentiation potentials of SBDCs for (A) chondrogenic, (B) osteogenic, and (C) adipogenic lineages in revision ARCR using immunostaining. (ARCR, arthroscopic rotator cuff repairs; SBDCs, subacromial bursa-derived cells.) 
study, the authors found that cells over the rotator cuff tendon had significantly better colony-forming ability than the cells taken over the rotator cuff muscle. They attributed this to the fact that the bursa over the tendon was more fibrous compared with the bursa over the muscle, which seemed to contain more adipose. This is consistent with other studies showing fibrous synovial tissue in the knee having greater proliferation potential and colony-forming ability than adipose synovium. ${ }^{25,40,41}$ Similarly, in our study, the bursa over the rotator cuff muscle in revision cases grossly contained more adipose tissue than the bursa over the rotator cuff muscle in primary cases. These findings paralleled those of rotator cuff fatty infiltration based on preoperative magnetic resonance imaging, with revision cases having a greater percentage of Goutallier grades 3 or 4 . Similar to Morikawa et al., ${ }^{12}$ the current study had lower colony-forming abilities from SBDCs harvested over the muscle belly, but only in revision cases. This finding may be secondary to the more acellular nature of adipose tissue, hindering the appreciated clonogenesis of these cells.

Revision rotator cuff repair poses a great challenge to surgeons and patients to achieve adequate healing and functional outcomes compared to primary repair. Augmentation with progenitor cells has shown promise in improving healing rates and clinical outcomes in patients undergoing primary rotator cuff repair but little has been studied about the role of these cells in the revision setting. ${ }^{8,35,42,43}$ Our study has demonstrated that the subacromial bursa is a significant source of CTPs that maintain their density and differentiation potential at the time of revision rotator cuff repair. These cells can be easily obtained and prepared at the time of surgery and used to augment repair. ${ }^{13}$ Further clinical studies are warranted to examine the effect SBDCs may have on the healing rates and clinical outcomes following revision rotator cuff repair.

\section{Limitations}

There are several limitations in this study. First, this is an in vitro study, and these results may not truly represent the in vivo potential of these CTPs in the shoulder. Second, variability in the results may be dependent on patient-specific factors, including medical comorbidities and previous treatments. However, this study was underpowered to detect these differences. Third, following bursectomy and subacromial decompression during the index surgery, the quantity of remaining healthy, harvestable subacromial bursa during revision repairs was not measured, which may limit its role as a local orthobiologic in the revision setting.

\section{Conclusions}

SBDCs harvested over the rotator cuff muscle demonstrated significantly decreased colony-forming abilities in revision ARCRs compared with primary repairs. However, the subacromial bursa retains its pluripotent differentiation potential for chondrogenic, osteogenic, and adipogenic lineages in the revision setting.

\section{References}

1. Yoo JC, Ahn JH, Koh KH, Lim KS. Rotator cuff integrity after arthroscopic repair for large tears with less-thanoptimal footprint coverage. Arthroscopy 2009;25: 1093-1100.

2. Galatz LM, Ball CM, Teefey SA, Middleton WD, Yamaguchi K. The outcome and repair integrity of completely arthroscopically repaired large and massive rotator cuff tears. J Bone Joint Surg 2004;86:219-224.

3. Mellado JM, Calmet J, Olona M, et al. Surgically repaired massive rotator cuff tears: MRI of tendon integrity, muscle fatty degeneration, and muscle atrophy correlated with intraoperative and clinical findings. AJR Am J Roentgenol 2005;184:1456-1463.

4. Kim IB, Kim MW. Risk factors for retear after arthroscopic repair of full-thickness rotator cuff tears using the suture bridge technique: Classification system. Arthroscopy 2016;32:2191-2200.

5. Patel S, Gualtieri AP, Lu HH, Levine WN. Advances in biologic augmentation for rotator cuff repair. Ann NY Acad Sci 2016;1383:97-114.

6. Lorbach O, Baums MH, Kostuj $\mathrm{T}$, et al. Advances in biology and mechanics of rotator cuff repair. Knee Surgery. Sport Traumatol Arthrosc 2015;23:530-541.

7. Imam MA, Holton J, Horriat S, et al. A systematic review of the concept and clinical applications of bone marrow aspirate concentrate in tendon pathology. SICOT J 2017;3:58.

8. Hernigou P, Flouzat Lachaniette $\mathrm{CH}$, Delambre J, et al. Biologic augmentation of rotator cuff repair with mesenchymal stem cells during arthroscopy improves healing and prevents further tears: A case-controlled study. Int Orthop 2014;38:1811-1818.

9. Degen RM, Carbone A, Carballo C, et al. The effect of purified human bone marrow-derived mesenchymal stem cells on rotator cuff tendon healing in an athymic rat. Arthroscopy 2016;32:2435-2443.

10. Uhthoff H, Sarkar K. Surgical repair of rotator cuff ruptures: The importance of the subacromial bursa. Bone Jt Surg Br 1991;73:399-401.

11. Steinert AF, Kunz M, Prager P, et al. Characterization of bursa subacromialis-derived mesenchymal stem cells. Stem Cell Res Ther 2015;6:1-14.

12. Morikawa D, Johnson JD, Kia C, et al. Examining the potency of subacromial bursal cells as a potential augmentation for rotator cuff healing: An in vitro study. Arthroscopy 2019;35:2978-2988.

13. Morikawa D, Muench LN, Baldino JB, et al. Comparison of preparation techniques for isolating subacromial bursaderived cells as a potential augment for rotator cuff repair. Arthroscopy 2020;36:80-85.

14. Muench LN, Baldino JB, Berthold DP, et al. Subacromial bursa-derived cells demonstrate high proliferation potential regardless of patient demographics and rotator cuff tear characteristics. Arthroscopy 2020;36:2794-2802. 
15. Baldino JB, Muench LN, Kia C, et al. Intraoperative and in vitro classification of subacromial bursal tissue. Arthroscopy 2020;36:2057-2068.

16. Landry A, Levy BJ, McCarthy MB, et al. Analysis of time to form colony units for connective tissue progenitor cells (stem cells) harvested from concentrated bone marrow aspirate and subacromial bursa tissue in patients undergoing rotator cuff repair. Arthrosc Sport Med Rehabil 2020;2: e629-e636.

17. Chillemi C, Petrozza V, Garro L, et al. Rotator cuff re-tear or non-healing: Histopathological aspects and predictive factors. Knee Surg Sport Traumatol Arthrosc 2011;19: 1588-1596.

18. Chillemi C, Petrozza V, Franceschini V, et al. The role of tendon and subacromial bursa in rotator cuff tear pain: A clinical and histopathological study. Knee Surg Sport Traumatol Arthrosc 2016;24:3779-3786.

19. Dyrna F, Zakko P, Pauzenberger L, McCarthy MB, Mazzocca AD, Dyment NA. Human subacromial bursal cells display superior engraftment versus bone marrow stromal cells in murine tendon repair. Am J Sports Med 2018:46:3511-3520.

20. Parnes N, DeFranco M, Wells JH, Higgins LD, Warner JJP. Complications after arthroscopic revision rotator cuff repair. Arthroscopy 2013;29:1479-1486.

21. Utsunomiya H, Uchida S, Sekiya I, Sakai A, Moridera K, Nakamura T. Isolation and characterization of human mesenchymal stem cells derived from shoulder tissues involved in rotator cuff tears. Am J Sports Med 2013;41: 657-668.

22. Futami I, Ishijima M, Kaneko $H$, et al. Isolation and characterization of multipotential mesenchymal cells from the mouse synovium. PLoS One 2012:7e45517.

23. Dominici M, Le Blanc K, Mueller I, et al. Minimal criteria for defining multipotent mesenchymal stromal cells. The International Society for Cellular Therapy position statement. Cytotherapy 2006:8:315-317.

24. Hatakeyama A, Uchida S, Utsunomiya H, et al. Isolation and characterization of synovial mesenchymal stem cell derived from hip joints: A comparative analysis with a matched control knee group. Stem Cells Int 2017;2017:8-10.

25. Katagiri K, Matsukura Y, Muneta T, et al. Fibrous synovium releases higher numbers of mesenchymal stem cells than adipose synovium in a suspended synovium culture model. Arthroscopy 2017;33:800-810.

26. Kanda Y. Investigation of the freely available easy-to-use software "EZR" for medical statistics. Bone Marrow Transpl 2013;48:452-458.

27. Warner JJP, Higgins L, Parsons IVIM, Dowdy P. Diagnosis and treatment of anterosuperior rotator cuff tears. J Shoulder Elbow Surg 2001;10:37-46.

28. Sears BW, Choo A, Yu A, Greis A, Lazarus M. Clinical outcomes in patients undergoing revision rotator cuff repair with extracellular matrix augmentation. Orthopedics 38:e292-e296.

29. Bishop J, Klepps S, Lo IK, Bird J, Gladstone JN, Flatow EL. Cuff integrity after arthroscopic versus open rotator cuff repair: A prospective study. J Shoulder Elbow Surg 2006;15: 290-299.
30. Björnsson HC, Norlin R, Johansson K, Adolfsson LE. The influence of age, delay of repair, and tendon involvement in acute rotator cuff tears. Acta Orthop 2011;82:187-192.

31. Boileau P, Brassart N, Watkinson DJ, Carles M, Hatzidakis AM, Krishnan SG. Arthroscopic repair of fullthickness tears of the supraspinatus. J Bone Joint Surg 2005;87:1229-1240.

32. Shamsudin A, Lam PH, Peters K, Rubenis I, Hackett L, Murrell GAC. Revision versus primary arthroscopic rotator cuff repair. Am J Sports Med 2015;43:557-564.

33. Thomopoulos S, Genin GM, Galatz LM. The development and morphogenesis of the tendon-to-bone insertion-what development can teach us about healing. J Musculoskelet neuronal Interact 2010;10:35-45.

34. Dyrna F, Herbst E, Hoberman A, Imhoff AB, Schmitt A. Stem cell procedures in arthroscopic surgery. Eur J Med Res 2016;21.

35. Gomes JLE, Silva RC da, Silla LMR, Abreu MR, Pellanda R. Conventional rotator cuff repair complemented by the aid of mononuclear autologous stem cells. Knee Surg Sport Traumatol Arthrosc 2012;20:373-377.

36. Gulotta LV, Kovacevic D, Montgomery S, Ehteshami JR, Packer JD, Rodeo SA. Stem cells genetically modified with the developmental gene MT1-MMP improve regeneration of the supraspinatus tendon-to-bone insertion site. Am J Sports Med 2010;38:1429-1437.

37. Gulotta LV, Kovacevic D, Packer JD, Deng XH, Rodeo SA. Bone marrow-derived mesenchymal stem cells transduced with scleraxis improve rotator cuff healing in a rat model. Am J Sports Med 2011;39:1282-1289.

38. Randelli P, Conforti E, Piccoli M, et al. Isolation and characterization of 2 new human rotator cuff and long head of biceps tendon cells possessing stem cell-like selfrenewal and multipotential differentiation capacity. Am J Sports Med 2013;41:1653-1664.

39. Song N, Armstrong AD, Li F, Ouyang H, Niyibizi C. Multipotent mesenchymal stem cells from human subacromial bursa: Potential for cell based tendon tissue engineering. Tissue Eng Part A 2014;20:239-249.

40. Neuwirth J, Fuhrmann RAE, Veit A, et al. Expression of bioactive bone morphogenetic proteins in the subacromial bursa of patients with chronic degeneration of the rotator cuff. Arthritis Res Ther 2006;8:R92.

41. Mochizuki T, Muneta T, Sakaguchi Y, et al. Higher chondrogenic potential of fibrous synovium- and adipose synovium-derived cells compared with subcutaneous fat-derived cells: Distinguishing properties of mesenchymal stem cells in humans. Arthritis Rheum 2006;54:843-853.

42. Kim YS, Sung CH, Chung SH, Kwak SJ, Koh YG. Does an injection of adipose-derived mesenchymal stem cells loaded in fibrin glue influence rotator cuff repair outcomes? A clinical and magnetic resonance imaging study. Am J Sports Med 2017;45:2010-2018.

43. Muench LN, Kia C, Berthold DP, et al. Preliminary clinical outcomes following biologic augmentation of arthroscopic rotator cuff repair using subacromial bursa, concentrated bone marrow aspirate, and platelet-rich plasma. Arthrosc Sport Med Rehabil 2020;2:e803-e813. 